\title{
Current perspectives on deep brain stimulation for severe neurological and psychiatric disorders
}

This article was published in the following Dove Press journal:

Neuropsychiatric Disease and Treatment

9 April 2015

Number of times this article has been viewed

\author{
Ersoy Kocabicak ${ }^{1-3}$ \\ Yasin Temel ${ }^{1,2}$ \\ Anke Höllig ${ }^{4}$ \\ Björn Falkenburger ${ }^{5}$ \\ Sonny KH Tan ${ }^{2,4}$ \\ 'Department of Neurosurgery, \\ Maastricht University Medical Centre, \\ ${ }^{2}$ Department of Neuroscience, \\ Maastricht University, Maastricht, \\ the Netherlands; ${ }^{3}$ Department \\ of Neurosurgery, Ondokuz \\ Mayıs University, Samsun, Turkey; \\ ${ }^{4}$ Department of Neurosurgery, \\ ${ }^{5}$ Department of Neurology, RWTH \\ Aachen University, Aachen, Germany
}

Correspondence: Sonny KH Tan Department of Neurosurgery, RWTH University Aachen, Pauwelsstrasse 30, 52074 Aachen, Germany

Email stan@ukaachen.de

\begin{abstract}
Deep brain stimulation (DBS) has become a well-accepted therapy to treat movement disorders, including Parkinson's disease, essential tremor, and dystonia. Long-term follow-up studies have demonstrated sustained improvement in motor symptoms and quality of life. DBS offers the opportunity to selectively modulate the targeted brain regions and related networks. Moreover, stimulation can be adjusted according to individual patients' demands, and stimulation is reversible. This has led to the introduction of DBS as a treatment for further neurological and psychiatric disorders and many clinical studies investigating the efficacy of stimulating various brain regions in order to alleviate severe neurological or psychiatric disorders including epilepsy, major depression, and obsessive-compulsive disorder. In this review, we provide an overview of accepted and experimental indications for DBS therapy and the corresponding anatomical targets.
\end{abstract}

Keywords: deep brain stimulation, movement disorders, neurological disorders, psychiatric disorders, Parkinson's disease

\section{Introduction}

Using electrical stimulation to modify brain function is an in fact old concept that has regained much attention over the last quarter of a century. ${ }^{1}$ Mostly referred to as deep brain stimulation (DBS), the procedure involves the intracerebral implantation of stimulation electrodes. These are connected to a subcutaneous pulse generator, which continuously delivers small electrical pulses. Activity of the targeted brain area and related brain networks are modulated. ${ }^{2,3}$

The application of DBS is accepted for the treatment of movement disorders, such as Parkinson's disease (PD), essential tremor (ET), and dystonia. Crucial for the success of DBS in movement disorders has been the introduction of an extensively studied model of basal ganglia circuitry. ${ }^{4-8}$ Conversely, the effects of DBS therapy have challenged and expanded the same model of basal ganglia circuitry. Encouraged by sustained results and clinical observations in movement disorders, clinicians were eager to treat further neurological disorders as well as psychiatric disorders. This development was encouraged by the rise of neurobiological explanations for psychiatric disorders and increasing evidence for dysfunctional brain networks underlying psychiatric symptoms. ${ }^{9-11}$ It is important to note that DBS is adjustable to individual demands, and stimulation is reversible. These features make DBS advantageous over ablative surgery, which was often used in the past to treat neurological and psychiatric disorders. Moreover, over the past 25 years, it has become clear that DBS surgery is a relatively safe procedure with low rates of morbidity and mortality, making it even more attractive.

In this review, we provide an overview of clinical DBS application in neurological and psychiatric disorders. We summarize well-accepted and experimental clinical 
indications and the different brain regions that have been targeted for neurological and psychiatric disorders.

\section{DBS for movement disorders}

\section{Parkinson's disease}

$\mathrm{PD}$ is a common neurodegenerative disorder characterized by tremor, rigidity, bradykinesia, and postural instability. Dopamine replacement treatment is the first-line treatment and significantly improves PD motor symptoms. ${ }^{12,13}$ Due to disease progression, patients often develop dopamine-resistant symptoms, motor fluctuations, and levodopa-induced dyskinesias. In addition, tremor is often not controlled well by medical therapy alone. It is estimated that $40 \%$ of PD patients suffer from motor fluctuations and $28 \%$ from levodopainduced dyskinesias. ${ }^{14}$

In 1987, Benabid et al used DBS of the ventral intermediate thalamic nuclei (Vim) in a PD patient to reduce tremor. ${ }^{15}$ However, in the later years, the preferred DBS target for PD shifted toward the subthalamic nucleus (STN). Meanwhile, DBS has become a well-accepted treatment for PD. The scientific basis for the successful application of DBS in PD is a widely used and intensively studied model of the basal ganglia referred to as the Albin-DeLong model. ${ }^{4-7}$ The STN is a key structure within the basal ganglia circuit and has been regarded a pacemaker of basal ganglia activity. ${ }^{8,16}$ Degeneration of dopamine neurons in the substantia nigra results in dysfunction of the basal ganglia-thalamocortical motor circuit. In 1-methyl-4-phenyl-1,2,3,6-tetrahydropyridine (MPTP)-treated parkinsonian monkeys, dopamine neurons degenerate, and the STN shows a shift toward bursting activity and hyperactivity. ${ }^{17-19}$ Pathological STN activity was associated with the onset of PD motor symptoms. Lesions of the STN improved tremor, rigidity, and bradykinesia in MPTP-treated monkeys. ${ }^{18}$ In 1993, Pollak et al described the potential of STN DBS in a patient with akinetic-rigid PD. ${ }^{20}$ Soon, many open-label and prospective trials followed showing significant improvement in PD motor disability ( $50 \%$ ) measured by the Unified Parkinson's Disease Rating Scale (UPDRS). ${ }^{21,22}$ A controlled randomized trial by Deuschl et al found improved quality of life (25\%) and confirmed the striking effects of STN DBS on motor function (41\% improvement) with superiority over best medical treatment. ${ }^{23}$ In addition, STN DBS plus best medical treatment has been shown to be superior over best medical treatment alone. ${ }^{24}$ Another advantage of STN DBS is the ability to reduce dopamine replacement therapy, offering a wider therapeutic range for medication and less undesired medication effects, including dyskinesias.
More recently, two long-term follow-up studies have been published. An 8-year follow-up study by Fasano et al demonstrated that STN DBS improves motor function by $55.5 \% 5$ years after surgery and by $39 \%$ after 8 years. ${ }^{25}$ Interestingly, the effect of STN DBS on tremor and rigidity remained stable over 5-8 years. Other motor symptoms showed a worsening after 8 years, which may reflect disease progression. The mean reduction in medication $(-60 \%)$ remained stable over 8 years. Cognitive function showed mild deterioration in various memory and verbal fluency tests. Hypophonia, eyelid opening apraxia, and weight gain were among the most reported side effects. Similarly, a 10-year follow-up study by Castrioto et al found a significant improvement in total UPDRS motor scores by STN DBS, particularly improving tremor and bradykinesia. ${ }^{26}$ There was also amelioration of dyskinesias and motor fluctuations. In contrast, axial symptoms did not improve over a course of 10 years.

Axial symptoms are not well addressed by STN DBS and become more pronounced with time. The exact mechanisms remain unclear. DBS of the substantia nigra pars reticulata (SNR) has been proposed to improve gait, but this was not confirmed. ${ }^{27}$ Axial symptoms are likely to develop outside the classic basal ganglia motor circuit and have been attributed to the pedunculo pontine nucleus (PPN) in the brainstem. ${ }^{28}$ Low-frequency STN DBS $(<80 \mathrm{~Hz})$ has been used to modulate the PPN. Although this may lead to gait improvement in selected patients, it does not seem to be effective in all studies. ${ }^{29,30}$ We note that direct PPN DBS may improve aspects of gait, ${ }^{31,32}$ but this finding needs further systematic clinical evaluation.

Initially, STN DBS surgery was performed $11-13$ years after disease onset. In this advanced stage, quality of life has already been compromised, and medication-resistant symptoms have appeared. This raised the question whether patients would benefit from surgery at an earlier time point. In the multicenter and randomized EARLY STIM trial, PD patients received STN DBS after mean disease duration of 7.5 years and within an average of 1.7 years after the onset of levodopa-related motor side effects. ${ }^{33}$ STN DBS significantly improved quality of life, emotion, and activities of daily living 2 years after surgery. UPDRS motor scores in the medication-off (stimulation-on) condition improved by $53 \%$ compared to a best medical treatment control group. Levodopa-related complications were also significantly reduced. The authors argued that best medical treatment was still effective at time point of surgery and DBS resulted in additional benefit. In the long run, these patients may benefit 
longer from both treatments and experience less treatment resistance.

Although STN is generally the preferred target for PD, there is a debate whether the STN is the optimal stimulation area. The globus pallidus internus (GPi), an important output nucleus of the basal ganglia, had been considered as an alternative target. A non-randomized trial suggested slight superiority for STN over GPi DBS. ${ }^{34}$ A highly anticipated multicenter and randomized trial by Follett et al demonstrated a similar improvement with STN and GPi DBS in both motor function and quality of life. ${ }^{35}$ STN DBS resulted in a larger medication reduction than GPi DBS but was also accompanied by a slightly more negative effect on mood. However, the results were criticized as the mean motor improvement in the STN group was lower than previous trials, which may have influenced the comparison. This was followed by a randomized study of Odekerken et al demonstrating a similar improvement in motor function for STN and GPi DBS. ${ }^{36}$ However, STN DBS was more effective in the drug-off phase and reduced drug requirements more. In line with open-label observations, GPi DBS resulted in less dyskinesias. It is suggested that STN DBS has a slight advantage over GPi DBS, but the latter may be suitable in selected patients presenting with psychiatric comorbidity, which is considered a contraindication for STN DBS.

Despite significant motor improvement, initial reports also described postoperative behavioral changes, including depression, apathy, and (hypo)mania. ${ }^{37} \mathrm{~A}$ retrospective multicenter study demonstrated increased risk of suicide and suicide attempts after STN DBS. ${ }^{38}$ A recent prospective trial did not find increased suicide risk or suicide ideation. ${ }^{39}$ Various mechanisms have been proposed for behavioral changes. We and others found STN DBS in animal models to cause a dysfunction of the central serotonin system. ${ }^{40-42}$ Changes in dopamine replacement therapy have also been held responsible. ${ }^{43}$ Psychosocial adjustments and accentuation of preexisting personality disorders may play a role as well. ${ }^{44}$ More recently, studies have demonstrated that STN DBS has become a cognitively safe procedure. ${ }^{45}$ This may be related to surgical experience, improved targeting techniques, and perioperative multidisciplinary management. For example, a lead trajectory through the caudate nucleus is now avoided, since it was associated with postoperative cognitive disturbances. ${ }^{46}$

Typically, a patient with idiopathic PD can be considered for DBS surgery when patients start to suffer from either insufficient motor symptom relief with medication or medication-induced side effects. However, levodopa responsiveness is an important criterion for DBS surgery. Contraindications for DBS surgery are generally considered to be dementia, active psychiatric disorders, dominant levodopa-resistant motor symptoms, and structural abnormalities in magnetic resonance images. These contraindications apply regardless of age. The ideal timing of DBS surgery is a matter of debate and is underlined by studies such as the above-mentioned EARLY STIM study. STN DBS is generally the first choice. However, GPi DBS can be considered in patients with severe dyskinesias and psychiatric comorbidities. Tremor-dominant PD, without or minimal rigidity and bradykinesia, may consider thalamic DBS.

\section{Severe tremor}

Tremor as a symptom of PD has to be distinguished from other tremor disorders. ET is a common movement disorder and defined as an action tremor of the (upper) limbs during voluntary movement. ${ }^{47}$ Approximately, $0.9 \%$ of people are affected by ET, and this percentage increases up to $4.5 \%$ in the age group over 65 years. The exact pathophysiology is unknown, but abnormal oscillatory activity in a network involving thalamus, olive cerebellum, and motor cortex appears responsible. ${ }^{48,49}$ In addition, severe and complex tremors may also occur in multiple sclerosis and after traumatic brain injury, cerebral hemorrhage, or infarction.

Severe tremor significantly impairs functions of daily living. Although tremor reduction can be achieved by propranolol or primidone, up to $30 \%$ of patients do not reach satisfactory tremor reduction or experience side effects. ${ }^{50}$ Thalamotomy was demonstrated to be very effective in improving severe tremor. ${ }^{51}$ However, cognitive impairment, dysarthria, and gait disturbances frequently occur, in particular after bilateral thalamotomy. Therefore, thalamic DBS has become the preferred surgical therapy. The stimulation electrodes are implanted into the Vim of the thalamus. Electrophysiological recordings in this area demonstrated neuronal activity correlating with muscle tremor. ${ }^{49}$ It was first introduced to treat severe tremor in PD and ET. ${ }^{52}$ This was followed by a study in 111 PD and ET patients, and the effects of Vim DBS were evaluated 1 year after surgery. Vim DBS resulted in a $75 \%$ reduction in the UPDRS tremor score in PD patients and 50\% improvement in essential tremor rating scale (ETRS) score in ET patients. ${ }^{53} \mathrm{~A}$ randomized study with patients suffering from PD, ET, and multiple sclerosis compared Vim DBS to thalamotomy. After 6 months, Vim DBS resulted in total or near-total tremor suppression in majority of patients ( $90 \%$ of patients), and this was comparable to thalamotomy ( $79 \%$ of patients). ${ }^{51}$ 
Functional recovery objectified by the Frenchay Activities Index after Vim DBS (+16\%) was greater than with thalamotomy $(+2 \%)$. In addition, side effects were fewer after Vim DBS, and bilateral DBS can be used to treat bilateral tremor. Follow-up studies in ET patients up to 7 years after surgery found significant reduction $(30 \%-46 \%)$ in ETRS. ${ }^{54,55}$ However, some suggest that there may be decline in tremor reduction by Vim DBS over time. Blomstedt et al found a $52 \%$ reduction in overall ETRS score after 1 year, and this was only $30 \%$ after 7 years. ${ }^{54}$ Interestingly, the decline was noticeable for action and intention tremor, and the effect on resting and postural tremor remained stable. However, others have demonstrated stable effects over time. ${ }^{55}$

DBS of Vim, of the ventral oralis posterior thalamus, or of zona incerta has also been applied to treat other more complex tremors, including tremor resulting from multiple sclerosis, and tremor resulting from hemorrhage, infarction, or trauma (Holmes tremor). In the above-mentioned randomized study, there was significant tremor reduction in a small number of multiple sclerosis patients after 6 months. ${ }^{51}$ Other small case series showed tremor reduction for these complex tremors, ${ }^{56-59}$ but the improvement was more variable and may decline over time. This is likely related to the varying location of the underlying brain injury.

Although the STN is the preferred target for PD-related motor disability, in selected cases, Vim DBS can be considered in tremor-dominant $\mathrm{PD}^{51}$ without severe rigidity and bradykinesia or in PD patients who have less favorable conditions for STN or GPi implantation, such as prominent neuropsychiatric comorbidities. A follow-up study of 6 years has shown sustained tremor improvement ( $82 \%$ reduction) in PD by Vim DBS. ${ }^{60}$

\section{Dystonia}

Dystonia is a movement disorder characterized by continuous and involuntary muscle contractions. These cause curling movements and abnormal postures, which are painful and debilitating. ${ }^{61}$ In generalized dystonia, the entire body is affected, whereas in segmental dystonia, only a part of the body is affected. In primary dystonia, the cause of the disease, such as trauma, stroke, or drugs, cannot be determined. In some patients, primary dystonia such as dystonia musculorum deformans or torsion dystonia-1 (DYT1) is associated with heterozygous mutation in the TOR1A gene. Botulinum toxin injections and pharmacological therapy may be unsatisfactory, and patients can develop severe motor and functional disability. Therefore, there is necessity for alternative treatment options. Although the pathophysiology is largely unclear, abnormal activity of the basal ganglia and in particular of the GPi has been suggested. ${ }^{62,63}$ Early observations reported a reduced firing rate of GPi neurons. Interrupting pallidal function with pallidotomy improved dystonia, but its beneficial effect diminished over time. The beneficial effect of GPi DBS on dyskinesias in PD patients supports a potential role for GPi DBS in dystonia. ${ }^{34}$

Coubes et al published the first open-label study showing improvement in dystonia in young patients suffering from DYT1-generalized dystonia after DBS of the posteroventral GPi. ${ }^{64}$ At 3 months, a mean reduction of $90 \%$ in Burke-Marsden-Fahn's dystonia rating scale (BMFDRS) was found, and there was a functional recovery. In contrast to PD where motor impairment rapidly disappears after stimulation onset, it is well established that symptoms of dystonia improve gradually and progressively over weeks to months. ${ }^{65}$

Prospective randomized controlled trials have confirmed these findings. GPi DBS improved primary generalized and segmental dystonia (50\%) and improved disability and quality of life 12 months after surgery. ${ }^{66,67}$ These clinical improvements were sustained up to 3-5 years after surgery. ${ }^{68-70}$ A single-center open-label study among DYT1 patients found an $86 \%$ and $91 \%$ improvement after 6 years in BMFDRS motor and disability scores, respectively, and effects even increased to $96 \%$ and $100 \%$ improvement after 8 years. However, the number of patients was limited at the latest assessment time points, only DYT1 patients were selected, and data were collected retrospectively. ${ }^{71}$ Also, cervical dystonia and dystonia choreoathetosis secondary to cerebral palsy were alleviated after 6-12 months, but the clinical benefit in both indications was lower $(\sim 25 \%)$ compared to primary generalized and segmental dystonia. ${ }^{72,73}$ Predictive factors for response to GPi DBS are considered to be the presence of DYT1 mutation, early disease onset, and shorter disease duration. ${ }^{74}$ Side effects that may complicate GPi DBS treatment are the onset of gait disturbances and bradykinesia.

Although GPi is generally the preferred target for dystonia, several studies have shown clinical benefits by DBS of the STN. ${ }^{75-77}$ It has even been suggested that STN and GPi DBS are equally effective. ${ }^{77}$ However, further research is required to verify this conclusion.

\section{DBS for epilepsy}

Epilepsy is a common neurological disorder with a prevalence of approximately $1 \%$ of the worldwide population. Despite best antiepileptic treatment, satisfactory clinical improvement is not achieved in approximately one-third 
of patients. ${ }^{78}$ Selected patients may benefit from resective surgery. However, some patients may not be eligible for resective surgery based on the involvement of eloquent areas, unclear or bilateral seizure onset, or a high risk of severe cognitive deterioration. Seizure suppression with electrical stimulation has been proposed by various stimulation techniques. Vagal nerve stimulation may result in long-term seizure reduction, but $25 \%$ of the patients do not benefit from this treatment, and seizure freedom is rare.

Most studies investigated the potential in seizure reduction by DBS of the anterior nucleus (AN) and centromedian nucleus $(\mathrm{CMN})$ of the thalamus. Initial small open-label studies showed promising reduction by AN DBS in seizure frequency $(>50 \%)$ up to 5 years of treatment in primary and secondary generalized epilepsy. ${ }^{79-81}$ More recently, the multicenter and controlled SANTE trial evaluated AN DBS in a cohort of 110 patients suffering from medically refractory partial seizures and secondary generalized seizures. ${ }^{78}$ During a 3-month blinded phase, AN DBS showed larger seizure reduction ( $-42 \%)$ compared to sham controls $(-28 \%)$. After 2 years, there was a median seizure reduction of $56 \%$, and quality of life was improved. Patients may experience paresthesias during DBS treatment. ${ }^{78}$ DBS of the CMN also significantly reduced generalized seizures $(>50 \%)$ after 12 -month follow-up. ${ }^{82}$ However, stimulation of this region seemed less effective for frontal epilepsy. Interestingly, several patients showed seizure reduction after $\mathrm{AN}$ and $\mathrm{CMN}$ electrode implantations without being stimulated. This insertion effect could last several months. ${ }^{78,79,82}$

Also, direct stimulation of mesiotemporal structures has been suggested in patients with temporal lobe epilepsy and complex partial seizures. In particular, patients with bilateral seizure onset and those with high risk of memory loss may not be considered candidates for resective surgery. Electrode implantation into mesiotemporal structures with and without hippocampal sclerosis reduced seizure frequency. Some patients even became seizure-free ${ }^{83-88}$ After stopping stimulation, the seizure frequency remained reduced, suggesting that neuroplasticity occurred. ${ }^{84}$ Some investigators suggested that seizure control was more pronounced in patients without magnetic resonance imaging abnormalities of the mesiotemporal lobe ${ }^{83}$ Others argued that seizure control may not be mediated through stimulation of the hippocampal focus itself but rather by the neighboring subilicum. ${ }^{89}$

Finally, several small studies also proposed to modulate the STN and SNR regions for epilepsy. Although clinical outcome may improve, its efficacy is still very uncertain. ${ }^{90,91}$

\section{DBS for psychiatric disorders}

Using electrical stimulation of subcortical structures to treat psychiatric disorders is an old concept that has been introduced over 50 years ago. ${ }^{1}$ The success of electrical stimulation in movement disorders has led to renewed interest in using DBS to treat psychiatric disorders. Changes in the conceptualization of psychiatric symptoms have been crucial for this development. Whereas psychiatric disorders were previously considered general problems of the entire brain, this view has now shifted toward dysfunctions of specific brain networks. Obsessive-compulsive disorder (OCD) and major depression (MD) have been most investigated.

\section{Obsessive-compulsive disorder}

OCD is characterized by unwanted repetitive thoughts and behaviors typically involving symmetry, taboo thoughts, contamination, and hoarding. ${ }^{11}$ It has been estimated that $2 \%$ of the worldwide population suffers from OCD. Primary treatment strategies include serotonin reuptake inhibitors and cognitive behavior therapy. Despite these treatments, approximately $10 \%$ of patients still suffer from treatment-refractory OCD. Selected cases may benefit from DBS. The brain regions that have been investigated most are the anterior limb of the internal capsule (ALIC), the nucleus accumbens (NAc), and the STN. The effects have generally been evaluated with Yale-Brown Obsessive Compulsive Scale (Y-BOCS) scores. A reduction of $>35 \%$ in Y-BOCS score has been used as the criterion for remission. A reduction between $25 \%$ and $35 \%$ in Y-BOCS score was considered partial response, and $<25 \%$ was interpreted as no-to-little change.

DBS was introduced to treatment-refractory OCD based on observations of ablative surgery and growing evidence for a pathophysiological mechanism involving a disturbance in the basal ganglia circuitry. Dysfunction of the basal ganglia and subsequent hyperactivity of the orbitofrontal cortex and anterior cingulate cortex have been held responsible for the onset of OCD symptoms. ${ }^{11}$

In a small series of patients, Nuttin et al reported improvement in OCD symptoms during DBS of the ALIC. ${ }^{92}$ Their target was based on results from capsulotomy studies. These encouraging results were followed by a randomized crossover study in four patients. ${ }^{93}$ In three patients, a decrease of at least 35\% in Y-BOCS scores was found. Greenberg et al evaluated the efficacy of DBS in the same region in ten severe OCD patients with a maximum follow-up of 3 years. ${ }^{94}$ In line with the data of Nuttin et al an improvement of $>35 \%$ in Y-BOCS score was found in half of the patients at the last 
follow-up moment. Data of the above studies were pooled together with data from other centers targeting the ALIC. The efficacy was evaluated in a total of 26 patients with a mean follow-up of 31 months. ${ }^{95}$ After 3 months of DBS, a mean decrease in Y-BOCS of approximately 30\% was reached, which was maintained until the last follow-up at 36 months. The percentage of patients who showed $>35 \%$ decrease in Y-BOCS and were regarded as responders increased with time. Patients who were operated more recently showed greater response to stimulation. In more recent operations, the target had been moved slightly more posteriorly where the ALIC neighbors the posterior ventral striatum. While high amplitudes (4-10.5 V) were required initially to obtain clinical effects, stimulation of the newer ALIC target was carried out with lower amplitudes suggesting closer proximity to the target responsible for the clinical benefit. Another important observation was that responders were primarily patients with obsessions and checking, whereas only half of the patients with symptoms involving symmetry and ordering or cleanliness and washing reached the response criteria. This suggests that different neurobiological mechanisms may underlie the different types of OCD symptoms.

The stimulation parameters of ALIC DBS were relatively high. This raised the question whether beneficial effects were actually mediated by the ALIC itself. Sturm et al hypothesized that the NAc, a ventral neighbor of the ALIC, was responsible for the improvement in OCD symptoms. ${ }^{96}$ The NAc is connected with the basal ganglia and frontal cortical areas, and is involved in the mesolimbic dopaminergic neurotransmission. Sturm et al, therefore, implanted electrodes with two contacts into the shell of the NAc, which is regarded the limbic subregion of this nucleus. The other two contacts were located in the ALIC. Interestingly, alleviation of OCD symptoms was only observed by stimulation of the NAc contacts and not with stimulation of the ALIC contacts. Moreover, the authors favored a unilateral right-sided NAc DBS. They did not find additive clinical improvement by bilateral NAc DBS. This approach was then used to treat ten OCD patients. After 1 year, half of the patients gradually developed an improvement of $>25 \%$ in Y-BOCS score and included one responder. ${ }^{97}$ The reduction in Y-BOCS score became more apparent with time. In addition, compulsions reduced greater than obsessions. At the same time, Denys et al evaluated bilateral NAc DBS for treatment-refractory OCD. In 16 patients, they reported a mean decrease in Y-BOCS score of 52\% over a period of 21 months, and nine patients were regarded as responders. ${ }^{98}$ During a short double-blind cross-over period, a significant difference was found between stimulation and sham conditions. Perfectionism, hoarding, and symmetry were less responsive to stimulation. More recently, closer analysis of the electrode positioning suggested that the most effective electrode contacts were actually located in the ventral part of the ALIC, directly neighboring the NAc core and bed nucleus stria terminalis. ${ }^{99}$ An interesting finding across the above-mentioned studies is the fact that many found improvements in depressive symptoms and anxiety. This underlines that various psychiatric symptoms probably share certain features or neurobiological mechanisms.

The third target for DBS in OCD patients is the STN. In PD, it was noticed that STN DBS improved repetitive behaviors and OCD symptoms. This encouraged Mallet et al to perform a randomized, double-blind study evaluating the effects of STN DBS in OCD. ${ }^{100}$ The electrode positioning within the STN was more anterior and medial compared to implantations for PD. In this way, the anatomical limbic and associative subdivisions of the STN were targeted rather than the STN motor subdivision. After a cross-over period, it became clear that 3 months of STN DBS significantly decreased Y-BOCS scores with a mean of $43 \%$ compared to sham conditions. Both compulsions and obsessions significantly improved. Unlike ALIC and NAc DBS, STN DBS did not alter depression and anxiety.

Until now, OCD is the only psychiatric disorder where DBS is accepted as a surgical treatment in patients refractory to medical and behavioral therapy. Moreover, these clinical studies have recently been reviewed by Hamani et al for an evidence-based guideline. ${ }^{101}$ The study by Mallet et al showing improvement by STN DBS is the only Class I evidence available at the moment. Class II evidence was provided by studies on NAc DBS. Both NAc and ALIC have shown clinical benefits in open-label studies and were therefore classified as Class III evidence. This underlines that the efficacy of DBS for OCD is supported by several well-designed trials (Table 1).

\section{Major depression}

MD is the topic within the field of DBS that has received most attention over the past few years. MD is very common and has a great impact on individuals and society. Most patients experience improvement in depressive symptoms by antidepressant drugs, cognitive behavior therapy, and electroconvulsive therapy. However, only $30 \%$ of patients reach remission, and $20 \%$ of patients are refractory to multimodal treatment. ${ }^{9}$ This has raised the interest in new treatment strategies including DBS. Crucial in this development was to regard MD as a 
disorder with a dysfunctional cortical-subcortical network involving prefrontal cortices, the mesolimbic system, and various brainstem neurotransmitter systems. ${ }^{10}$ The DBS targets that have been most investigated for MD include the subgenual cingulate gyrus (SCG; Brodmann Area 25), ALIC, and NAc. Mood improvement and response to DBS were generally evaluated by changes in depression scales (eg, Hamilton Depression Rating Scale, HDRS) with a decrease in depression score $>50 \%$ as marker for response and HDRS $<8-10$ points for remission.

Mayberg proposed a brain circuit of depression with a key function for the SCG. ${ }^{9}$ This area showed hypermetabolism in depression and was activated by negative emotion. Moreover, antidepressant therapies reversed this hypermetabolism. It was hypothesized that functional inactivation by SCG DBS might alleviate MD. In a proof-of-concept study, six treatment-refractory MD patients showed an improvement in depression by DBS in the SCG. ${ }^{102}$ After 6 months, four out of six patients showed a decline of $>50 \%$ in HDRS, and three of them reached (near)-remission. As expected, regional blood flow was locally decreased in the SCG. Another 14 patients underwent SCG DBS and in their cohort of all together 20 patients, the Toronto group found a progressive improvement of depression. ${ }^{103}$ After 6 months, $60 \%$ of patients were responders, and $35 \%$ achieved remission. It was suggested that a maximum benefit of SCG DBS was reached at 6 months. At 1 year, $55 \%$ of the patients were still responders, and the number of (near)-remission remained stable. Not only mood but also somatic symptoms, including anxiety and sleep pattern, were improved. This striking antidepressant effect was sustained 3-6 years after surgery, with response rates of $55 \%-60 \%$ and $35 \%$ of patients in remission. Moreover, patients showed functional recovery, and many went back to work. ${ }^{104}$ SCG DBS was also evaluated in a mixed population with MD and bipolar disorder. After 2 years, $92 \%$ of patients were classified as responders, and 58\% were in remission. ${ }^{105}$ This suggested that SCG DBS may also be suitable for refractory bipolar disorder. It was later proposed that the effects of DBS in the SCG are actually mediated by white matter bundles connecting frontal cortices and NAc. ${ }^{106}$

The second brain region that was investigated in MD was the NAc. This area is centrally located in the mesolimbic system and associated with reward-related symptoms of depression. Schlaepfer et al demonstrated immediate motivational and reward-seeking behavior in three patients undergoing bilateral NAc DBS. Clinical depression rating scales showed improvement as well. ${ }^{107}$ Bewernick et al confirmed NAc DBS to acutely improve depression, anxiety, and anhedonia. ${ }^{108}$ 


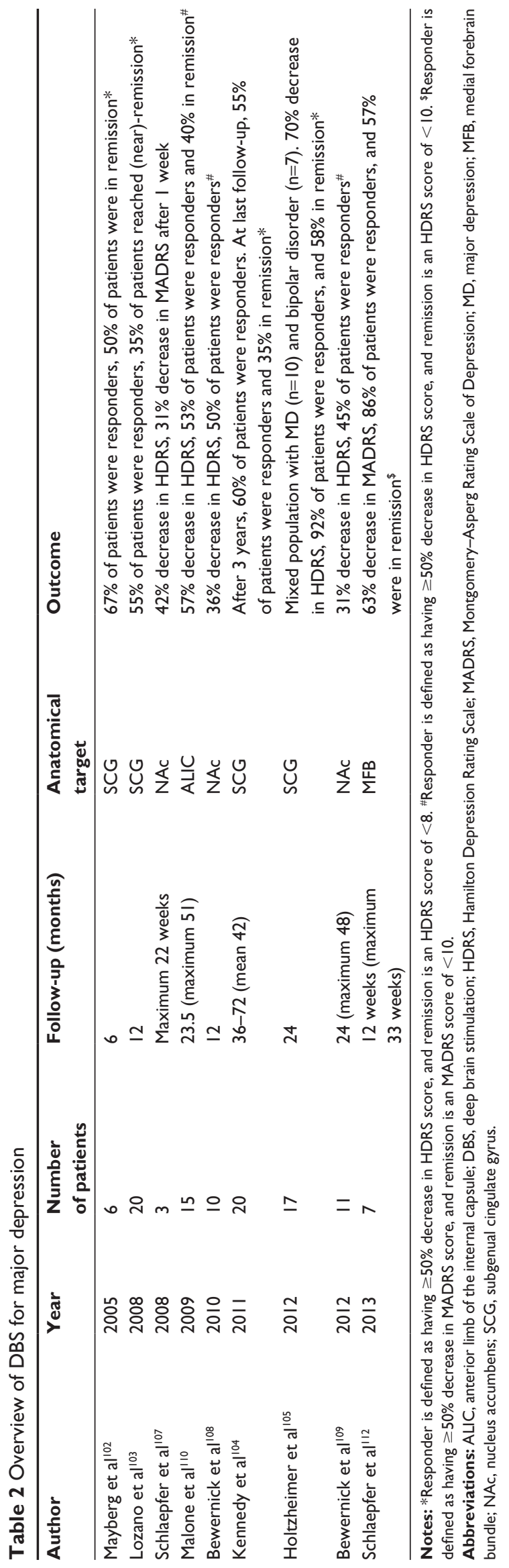

After 1 year, five out of ten patients were classified as responders ( $>50 \%$ decrease in HDRS). These antidepressant effects were maintained up to 4 years after surgery. ${ }^{109}$

The third anatomical target is the ALIC. Stimulation of this brain area for OCD improved mood. This triggered Malone et al to evaluate ALIC DBS for MD. In a study population of 15 patients, approximately $50 \%$ of patients were considered responders from 3 months after surgery up to their last follow-up moment at a mean of 2 years. ${ }^{10}$

Altogether the SCG, NAc, and ALIC seem to result in similar magnitude of response rates. DBS of some targets required high voltages. Anatomical reconstructions by Coenen et al proposed that these three targets actually modulate the medial forebrain bundle (MFB). ${ }^{111}$ Moreover, the (superolateral) MFB is centrally located in the mesolimbic reward system. The MFB is close to the ventral tegmental area and projects to forebrain regions such as the NAc and prefrontal cortex. They performed an uncontrolled pilot study in seven patients with MD. In six patients, MFB DBS improved depression scores ( $>50 \%$ reduction in MADRS) after 1 week of stimulation. ${ }^{12}$ This clinical improvement persisted up to 33 weeks after DBS was initiated.

Besides these relatively small studies (Table 2), there have been various case reports that suggested antidepressant effects with DBS of the inferior thalamic peduncle ${ }^{113}$ and of the stria medullaris thalami, which is a major afferent bundle to the lateral habenula. ${ }^{114}$ The lateral habenula is a regulator of dopamine and serotonin neurotransmission. It has demonstrated abnormal activity in MD, and its activity has been associated with symptoms of depression. ${ }^{115,116}$

\section{DBS for experimental clinical indications}

Based on clinical observations among patients treated for the above-mentioned movement disorders and psychiatric disorders, new but highly experimental DBS indications have been proposed.

\section{DBS for Tourette's syndrome}

Tourette's syndrome (TS) is a neuropsychiatric disorder characterized by motor and vocal tics. ${ }^{117}$ Key aspect of the TS pathophysiology appears to be dysfunctional activity in sensorimotor and limbic parts of basal ganglia and thalamus. ${ }^{117}$ DBS of key areas within the basal ganglia and thalamus has been suggested to improve systems in patients exhibiting life-threatening self-injury or severe tics entailing significant functional impairment and failing to respond to noninvasive therapy. 
Over the past 2 decades, more than 90 patients with TS have been reported to be treated with DBS and with various stimulation targets. First, the thalamic region where the CMN, substantia periventricularis, and nucleus ventro-oralis internus cross was proposed as an anatomical target based on thalamotomy studies by Vandewalle et $\mathrm{al}^{118}$ and had been used by different groups. ${ }^{118-125}$ The group of Porta and Servello slightly changed this thalamic target and positioned their electrodes $2 \mathrm{~mm}$ more anteriorly. ${ }^{126-128}$ Others have targeted the center of the $\mathrm{CMN}^{129}$ and the dorsomedial thalamus. ${ }^{130,131}$ Targets outside the thalamus have included the globus pallidus externus ${ }^{132}$ and the ventroposterolateral motor and the anteromedial limbic part of the GPi. ${ }^{133-139}$ TS patients with comorbid OCD have also been treated with DBS of the NAc ${ }^{140-144}$ and the internal capsule. ${ }^{124,140,143}$ Finally, tics improvement was also observed in a PD patient with tics, who was treated with STN DBS. ${ }^{145}$ More detailed information about the targets and their results are described in reviews by Pansaon Piedad et al, ${ }^{146}$ Groenewegen et al, ${ }^{147}$ and ourselves. ${ }^{148}$

The above-mentioned case series and reports illustrate two difficulties in the field of DBS in TS. The first is that the reported number of cases is relatively low, which might be related to the low prevalence of severe TS cases. The second is the diversity of the targets. Even though one could argue that these regions are parts of circuits, we feel that the diversity of targets in TS reflects the lack of a clear pathophysiological concept of severe TS. This is further complicated by changes in symptoms over time and frequent comorbidities such as OCD and depression.

\section{Huntington's disease}

Huntington's disease (HD) is an autosomal dominant and progressive neurodegenerative disorder. ${ }^{149}$ The disease is caused by a strongly increased number of trinucleotide CAG repeats in the Huntingtin gene and characterized by a progressive loss of striatal neurons. Phenotypically, patients present with severe motor symptoms, such as chorea, dystonia, and bradykinesia. Disability is further complicated by cognitive and psychiatric symptoms. Current treatment options are limited, and symptomatic relief is often unsatisfactory. Similar to PD, the basal ganglia motor circuit provides a neurobiological model for HD symptoms as one of its key structures shows degeneration.

Since choreodystonic movements in PD were improved by GPi DBS, ${ }^{34}$ several case reports and small series have evaluated the efficacy of GPi DBS on HD symptoms.
Most patients who underwent GPi DBS had chorea-dominant symptoms, stable neuropsychiatric performance, and no active psychiatric disorder. Chorea was immediately improved after stimulation onset and was reduced up to $76 \%$ after 1 year and 56\% after 5 years in the Unified Huntington's Disease Rating Scale chorea score. ${ }^{150-158}$

The effect on other HD motor symptoms was variable. Moro et al described simultaneous alleviation in dystonia with low- $(40 \mathrm{~Hz})$ and high-frequency $(130 \mathrm{~Hz})$ stimulation but also worsening of bradykinesia with the latter paradigm. ${ }^{150}$ This frequency dependency of motor symptoms was not consistently reproduced by others. ${ }^{151,157,158}$ Although chorea improvement was generally maintained over time, some authors found no significant change in other motor symptoms, ${ }^{154}$ and others found progressive motor and cognitive deterioration. ${ }^{151,152,156,157}$ These differential effects may be related to variability in disease course but may also indicate different pathological mechanisms.

Ligot et al described changes in connectivity during DBS of the globus pallidus externus in five HD patients measured by $\mathrm{H}_{2}{ }^{15} \mathrm{O}-\mathrm{PET}^{159}$ in regions of the basal gangliathalamocortical circuit. However, clinical outcome of these patients was not reported, and it remained unclear whether their findings were supported by improvement in HD motor symptoms.

\section{Memory impairment}

The concept of memory restoration by DBS is very intriguing. This topic was more recently highlighted by Hamani et al reporting on a patient who was treated with bilateral DBS of the ventral hypothalamus and experienced vivid "déjà vu" moments. ${ }^{160}$ Reconstruction of the electrode localization showed that the electrode contacts that evoked these memories were close to the fornix. This white matter bundle connects the hippocampus and mammillary bodies among others. Hippocampal function was altered by stimulation and showed improvement in aspects of learning and recollection of memory. These effects were related to increased activity of mesiotemporal lobe structures.

This case report triggered investigations to explore the use of hypothalamus/fornix DBS to drive memory function in dementia. Alzheimer's disease is the most common neurodegenerative disorder presenting with progressive memory deterioration. Its prevalence is expected to increase in the years to come. Six patients with early or mild Alzheimer's disease participated in an open-label study. ${ }^{161}$ Over a 12-month period, a slight deterioration in neuropsychological performance was found measured by the Alzheimer's 
disease assessment scale, cognitive subscale (ADAS-Cog). Compared to estimated natural deterioration in ADAS-Cog, it was suggested that cognitive decline in the stimulated patients was slower than expected. But there were also patients with similar or faster cognitive decline compared to historic controls.

Memory restoration has also been investigated by direct stimulation of the hippocampal area by Suthana et al. ${ }^{162}$ In a group of seven epilepsy patients with depth electrodes to locate seizure foci, memory function was assessed by direct stimulation of the entorhinal cortex in six patients. They observed an improvement in spatial learning. Interestingly, this effect was not observed by stimulation of the hippocampus itself.

Instead of driving the hippocampal system, others have focused on the cholinergic system. ${ }^{163}$ Degeneration of the cholinergic system is typical for Alzheimer's disease. Moreover, symptoms of Alzheimer's disease correlate with loss of acetylcholine tone and pathology of the cholinergic neurons. Drugs used to treat AD enhance acetylcholine neurotransmission. Main cholinergic neurons are located in the basal forebrain and in particular in the nucleus basalis of Meynert (NBM), which project to the hippocampus and neocortex. Freund et al treated a PD patient with dementia. ${ }^{164}$ In addition to STN DBS electrodes, the patient received bilateral electrode implantations into the NBM. The NBM was stimulated with a low-frequency paradigm $(20 \mathrm{~Hz})$. Cognitive and memory functions improved. ${ }^{163}$ Recently, in a double-blind sham-controlled pilot study, the effect of NBM DBS was tested in six Alzheimer's patients with mild-to-moderate disease. ${ }^{165}$ In a short 4-week cross-over period, there was no significant change. After an open-label period of 11 months, patients showed a moderate worsening of ADAS-Cog and minimal change in mini mental status examination. These changes were actually lower than the expected deterioration based on the literature of comparable patient populations without stimulation.

\section{Anorexia nervosa}

Anorexia nervosa mainly affects young female patients. The inability to maintain normal body weight is accompanied by a fear to gain weight, a distorted body image, and personality traits including perfectionism. ${ }^{166}$ A long disease course with frequent relapses leads to comorbidities and often requires hospitalization. Comorbidities include depression, OCD, and anxiety disorders. Imaging studies suggest similarities in the underlying neurobiological circuitry. Accordingly, a case report of a 48-year-old patient suffering from OCD showed that DBS with active stimulation of the ventral caudate and ventral ALIC improved symptoms of anorexia nervosa. ${ }^{167}$

Several further small open-label studies and case reports have treated anorexia nervosa patients with DBS of SCG and NAc, which have been investigated in the context of depression and OCD as described above. Israel et al described beneficial effects of SCG DBS on body weight and persisting remission in a 56-year-old female anorexia nervosa patient. ${ }^{168}$ In a small open-label study, six female patients received SCG DBS. Although patients initially lost weight in the first 2 months after surgery, three out of six had higher body mass index after 9 months of stimulation, and three others remained at their baseline body weight. ${ }^{169}$ In addition, improvements in depression and anxiety were found. In another study, four adolescent females received DBS of the medioventral NAc. After a mean follow-up of 38 months, a significant gain in body weight was observed $(+65 \%) .{ }^{170}$ All patients did no longer fulfill the diagnostic criteria for anorexia nervosa, and menstruation cycles were restored.

It should be noted that the number of patients is very small, and definite conclusions are very difficult to draw. The influence of natural fluctuations in body weight during the disease course and the role of psychiatric comorbidities have to be taken into account. At the same time, the positive observations do provide some additional information to better understand the neurobiology of this severe and debilitating disorder.

\section{Addiction}

Addiction for substances including alcohol, nicotine, and heroin represents a significant risk for personal health and entails major socioeconomic problems. Addiction is accompanied by high comorbidity and mortality. Addiction is also characterized by high relapse rates.

Remarkable changes in addictive behavior were observed in patients who were primarily treated for OCD, anxiety, and TS with NAc DBS. These patients showed remission or reduced alcohol and nicotine abuse. ${ }^{171,172}$ This was subsequently followed by several small case studies showing DBS of the NAc/ALIC region to improve addiction for alcohol and heroin. ${ }^{173-176}$ Reduction in craving was reported, and some patients even remained abstinent after surgery. Others experiencing relapses noticed that they were less frequent and less intense.

Finally, some PD patients may develop addiction to high doses of dopamine medication. STN DBS has been shown to improve this addiction in PD patients. ${ }^{177}$ As mentioned above, STN DBS leads to significant motor improvement, 
and dopamine replacement therapy can be reduced substantially. Pulsatile high peaks of dopamine will not occur anymore, which may be responsible for the improvement of addiction. But also a direct effect of STN DBS on the mesolimbic reward circuitry has been suggested.

\section{Discussion and conclusion}

Over the past 25 years, DBS has gained a prominent position in the treatment of refractory movement disorders by modulation of the basal ganglia-thalamocortical circuit. In particular, PD and dystonia have extensively been studied using models of basal ganglia dysfunction, which can explain their key symptoms. The improvements in motor function and quality of life have been confirmed by randomized controlled trials and long-term follow-up studies..$^{23,25,26}$ In PD, both STN and GPi DBS result in significant improvement of motor function. ${ }^{35,36}$ However, the STN is generally preferred over the GPi, since the STN offers additional advantages such as a reduction in dopamine replacement therapy. ET can be treated with Vim DBS with great tremor reduction. ${ }^{51}$ Advantages of Vim DBS over thalamotomy include greater functional recovery and less cognitive disturbances during stimulation, and the possibility to perform bilateral treatment. However, more research is necessary to understand the long-term efficacy of DBS for secondary tremor, for example, related to multiple sclerosis or stroke. Primary generalized and segmental dystonia are alleviated by GPi DBS. ${ }^{21,66-69}$ The clinical improvements can be maintained over years. Evidence also suggests benefits in secondary dystonia, but these may be less pronounced or predictable. Clinical improvement of dystonia occurs slowly, which contrasts the acute changes in PD and tremor.

Besides these well-accepted indications in movement disorders, DBS also shows promising effects in other neurological disorders, such as epilepsy, and in psychiatric disorders. Treatment-refractory OCD has become an accepted indication for DBS. STN DBS showed significant reduction in OCD symptoms, which was regarded as Class I evidence. ${ }^{100,101}$ Moreover, efficacy of NAc DBS in OCD has been classified as Class II evidence, and other studies showing benefits by ALIC DBS are regarded as Class III evidence. ${ }^{98,101}$ Recently, a lot of attention was generated for DBS in MD. Various DBS targets, including the SCG, NAc, and ALIC, showed encouraging and interesting antidepressant effects. ${ }^{102,104,107,108,110}$ However, these studies have generally been conducted with a small number of patients and require confirmation in randomized controlled trials. Moreover, several other brain targets, such as the MFB and lateral habenula, ${ }^{112,114}$ have been proposed in small series and case studies. The field of DBS has also expanded rapidly with highly experimental indications. These have mainly risen from coincidental findings from above-mentioned studies, such as restoration of memory and eating behavior. Potential benefits by DBS have been proposed in Alzheimer's disease, addiction, and anorexia nervosa. ${ }^{161,165,169,174}$ But these results still have to be interpreted with a lot of caution and require further investigation.

Altogether, it is clear that besides the well-established indications for DBS, many new neurological and psychiatric disorders are proposed to be treated with stimulation. This has led to the implantation of stimulation electrodes in many different brain regions. The growing number of targeted brain regions and their potential to improve neurological and psychiatric symptoms also require preclinical research to understand the underlying mechanisms. Which brain networks are dysfunctional and what are the optimal targets for each new disorder? It is of utmost importance in the field of DBS that for experimental indications, sufficient and welldesigned trials be performed to allow direct comparison of target areas and identification of inclusion criteria. New technological advances will be helpful to allow more specific stimulation and further improve surgical techniques. Also, experimental research in animal models is and will be of great value to understand neurobiological mechanisms for experimental indications of DBS. They will provide insight into molecular, electrophysiological, and behavioral aspects of the underlying disorders on the one hand and into the mechanism of action of DBS on the other.

\section{Disclosure}

The authors report no conflicts of interest in this work.

\section{References}

1. Hariz MI, Blomstedt P, Zrinzo L. Deep brain stimulation between 1947 and 1987: the untold story. Neurosurg Focus. 2010;29(2):E1.

2. Deniau JM, Degos B, Bosch C, Maurice N. Deep brain stimulation mechanisms: beyond the concept of local functional inhibition. Eur $J$ Neurosci. 2010;32(7):1080-1091.

3. Lozano AM, Dostrovsky J, Chen R, Ashby P. Deep brain stimulation for Parkinson's disease: disrupting the disruption. Lancet Neurol. 2002; 1(4):225-231.

4. Albin RL, Young AB, Penney JB. The functional anatomy of basal ganglia disorders. Trends Neurosci. 1989;12(10):366-375.

5. Alexander GE, Crutcher MD. Functional architecture of basal ganglia circuits: neural substrates of parallel processing. Trends Neurosci. 1990; 13(7):266-271.

6. Parent A, Hazrati LN. Functional anatomy of the basal ganglia. I. The cortico-basal ganglia-thalamo-cortical loop. Brain Res Brain Res Rev. 1995; 20(1):91-127.

7. Smith Y, Bevan MD, ShinkE, Bolam JP. Microcircuitry of the direct and indirect pathways of the basal ganglia. Neuroscience. 1998;86(2):353-387. 
8. Temel Y, Blokland A, Steinbusch HW, Visser-Vandewalle V. The functional role of the subthalamic nucleus in cognitive and limbic circuits. Prog Neurobiol. 2005;76(6):393-413.

9. Mayberg HS. Targeted electrode-based modulation of neural circuits for depression. J Clin Invest. 2009;119(4):717-725.

10. Nestler EJ, Barrot M, DiLeone RJ, Eisch AJ, Gold SJ, Monteggia LM. Neurobiology of depression. Neuron. 2002;34(1):13-25.

11. Pauls DL, Abramovitch A, Rauch SL, Geller DA. Obsessive-compulsive disorder: an integrative genetic and neurobiological perspective. Nat Rev Neurosci. 2014;15(6):410-424.

12. Lees AJ, Hardy J, Revesz T. Parkinson's disease. Lancet. 2009;373(9680): 2055-2066.

13. Rodriguez-Oroz MC, Jahanshahi M, Krack P, et al. Initial clinical manifestations of Parkinson's disease: features and pathophysiological mechanisms. Lancet Neurol. 2009;8(12):1128-1139.

14. Schrag A, Quinn N. Dyskinesias and motor fluctuations in Parkinson's disease. A community-based study. Brain. 2000;123(pt 11): 2297-2305.

15. Benabid AL, Pollak P, Louveau A, Henry S, de Rougemont J. Combined (thalamotomy and stimulation) stereotactic surgery of the VIM thalamic nucleus for bilateral Parkinson disease. Appl Neurophysiol. 1987;50(1-6):344-346.

16. Plenz D, Kital ST. A basal ganglia pacemaker formed by the subthalamic nucleus and external globus pallidus. Nature. 1999;400(6745): $677-682$.

17. Miller WC, DeLong MR. Altered tonic activity of neurons in the globus pallidus and subthalamic nucleus in the primate model of Parkinsonism. In: Carpenter MB, Jayaraman A, editors. The Basal Ganglia II: Structure and Function. New York: Springer; 1987:415-427.

18. Bergman H, Wichmann T, DeLong MR. Reversal of experimental Parkinsonism by lesions of the subthalamic nucleus. Science. 1990;249(4975):1436-1438.

19. Bergman H, Wichmann T, Karmon B, DeLong MR. The primate subthalamic nucleus. II. Neuronal activity in the MPTP model of Parkinsonism. J Neurophysiol. 1994;72(2):507-520.

20. Pollak P, Benabid AL, Gross C, et al. Effets de la stimulation du noyau sousthalamique dans la maladie de Parkinson [Effects of the stimulation of the subthalamic nucleus in Parkinson disease]. Rev Neurol (Paris). 1993; 149(3):175-176. French.

21. Krack P, Batir A, Van Blercom N, et al. Five-year follow-up of bilateral stimulation of the subthalamic nucleus in advanced Parkinson's disease. N Engl J Med. 2003;349(20):1925-1934.

22. Rodriguez-Oroz MC, Obeso JA, Lang AE, et al. Bilateral deep brain stimulation in Parkinson's disease: a multicentre study with 4 years follow-up. Brain. 2005;128(pt 10):2240-2249.

23. Deuschl G, Schade-Brittinger C, Krack P, et al. A randomized trial of deep-brain stimulation for Parkinson's disease. $N$ Engl J Med. 2006;355(9):896-908.

24. Williams A, Gill S, Varma T, et al. Deep brain stimulation plus best medical therapy versus best medical therapy alone for advanced Parkinson's disease (PD SURG trial): a randomised, open-label trial. Lancet Neurol. 2010;9(6):581-591.

25. Fasano A, Romito LM, Daniele A, et al. Motor and cognitive outcome in patients with Parkinson's disease 8 years after subthalamic implants. Brain. 2010;133(9):2664-2676.

26. Castrioto A, Lozano AM, Poon YY, Lang AE, Fallis M, Moro E. Ten-year outcome of subthalamic stimulation in Parkinson disease: a blinded evaluation. Arch Neurol. 2011;68(12):1550-1556.

27. Weiss D, Walach M, Meisner C, et al. Nigral stimulation for resistant axial motor impairment in Parkinson's disease? A randomized controlled trial. Brain. 2013;136(pt 7):2098-2108.

28. Tattersall TL, Stratton PG, Coyne TJ, et al. Imagined gait modulates neuronal network dynamics in the human pedunculopontine nucleus. Nat Neurosci. 2014;17(3):449-454.

29. Sidiropoulos C, Walsh R, Meaney C, Poon YY, Fallis M, Moro E. Low-frequency subthalamic nucleus deep brain stimulation for axial symptoms in advanced Parkinson's disease. J Neurol. 2013;260(9): 2306-2311.
30. Moreau C, Defebvre L, Destee A, et al. STN-DBS frequency effects on freezing of gait in advanced Parkinson disease. Neurology. 2008;71(2): 80-84.

31. Thevathasan W, Coyne TJ, Hyam JA, et al. Pedunculopontine nucleus stimulation improves gait freezing in Parkinson disease. Neurosurgery. 2011;69(6):1248-1253. [discussion 54].

32. Ferraye MU, Debu B, Fraix V, et al. Effects of pedunculopontine nucleus area stimulation on gait disorders in Parkinson's disease. Brain. 2010;133(pt 1):205-214.

33. Schupbach WM, Chastan N, Welter ML, et al. Stimulation of the subthalamic nucleus in Parkinson's disease: a 5 years follow up. J Neurol Neurosurg Psychiatry. 2005;76(12):1640-1644.

34. Deep-Brain Stimulation for Parkinson's Disease Study Group. Deep-brain stimulation of the subthalamic nucleus or the pars interna of the globus pallidus in Parkinson's disease. $N$ Engl J Med. 2001;345(13):956-963.

35. Follett KA, Weaver FM, Stern M, et al. Pallidal versus subthalamic deep-brain stimulation for Parkinson's disease. $N$ Engl J Med. 2010;362(22):2077-2091.

36. Odekerken VJ, van Laar T, Staal MJ, et al. Subthalamic nucleus versus globus pallidus bilateral deep brain stimulation for advanced Parkinson's disease (NSTAPS study): a randomised controlled trial. Lancet Neurol. 2013;12(1):37-44.

37. Temel Y, Kessels A, Tan S, Topdag A, Boon P, Visser-Vandewalle V. Behavioural changes after bilateral subthalamic stimulation in advanced Parkinson disease: a systematic review. Parkinsonism Relat Disord. 2006;12(5):265-272.

38. Voon V, Krack P, Lang AE, et al. A multicentre study on suicide outcomes following subthalamic stimulation for Parkinson's disease. Brain. 2008;131(pt 10):2720-2728.

39. Weintraub D, Duda JE, Carlson K, et al. Suicide ideation and behaviours after STN and GPi DBS surgery for Parkinson's disease: results from a randomised, controlled trial. J Neurol Neurosurg Psychiatry. 2013;84(10):1113-1118.

40. Navailles S, Benazzouz A, Bioulac B, Gross C, De Deurwaerdere P. High-frequency stimulation of the subthalamic nucleus and L-3,4dihydroxyphenylalanine inhibit in vivo serotonin release in the prefrontal cortex and hippocampus in a rat model of Parkinson's disease. J Neurosci. 2010;30(6):2356-2364.

41. Tan SK, Hartung H, Visser-Vandewalle V, Steinbusch HW, Temel Y, Sharp T. A combined in vivo neurochemical and electrophysiological analysis of the effect of high-frequency stimulation of the subthalamic nucleus on 5-HT transmission. Exp Neurol. 2012;233(1): $145-153$.

42. Temel Y, Boothman LJ, Blokland A, et al. Inhibition of 5-HT neuron activity and induction of depressive-like behavior by high-frequency stimulation of the subthalamic nucleus. Proc Natl Acad Sci US A. 2007; 104(43):17087-17092.

43. Thobois S, Ardouin C, Lhommee E, et al. Non-motor dopamine withdrawal syndrome after surgery for Parkinson's disease: predictors and underlying mesolimbic denervation. Brain. 2010;133 (pt 4):1111-1127.

44. Tan SK, Hartung H, Sharp T, Temel Y. Serotonin-dependent depression in Parkinson's disease: a role for the subthalamic nucleus? Neuropharmacology. 2011;61(3):387-399.

45. Witt K, Daniels C, Reiff J, et al. Neuropsychological and psychiatric changes after deep brain stimulation for Parkinson's disease: a randomised, multicentre study. Lancet Neurol. 2008;7(7):605-614.

46. Witt K, Granert O, Daniels C, et al. Relation of lead trajectory and electrode position to neuropsychological outcomes of subthalamic neurostimulation in Parkinson's disease: results from a randomized trial. Brain. 2013;136(pt 7):2109-2119.

47. Deuschl G, Bain P, Brin M. Consensus statement of the Movement Disorder Society on Tremor. Ad Hoc Scientific Committee. Mov Disord. 1998;13(suppl 3):2-23.

48. Louis ED. Essential tremor: evolving clinicopathological concepts in an era of intensive post-mortem enquiry. Lancet Neurol. 2010;9(6): 613-622. 
49. Raethjen J, Deuschl G. The oscillating central network of Essential tremor. Clin Neurophysiol. 2012;123(1):61-64.

50. Elias WJ, Shah BB. Tremor. JAMA. 2014;311(9):948-954.

51. Schuurman PR, Bosch DA, Bossuyt PM, et al. A comparison of continuous thalamic stimulation and thalamotomy for suppression of severe tremor. N Engl J Med. 2000;342(7):461-468.

52. Benabid AL, Pollak P, Gervason C, et al. Long-term suppression of tremor by chronic stimulation of the ventral intermediate thalamic nucleus. Lancet. 1991;337(8738):403-406.

53. Limousin P, Speelman JD, Gielen F, Janssens M. Multicentre European study of thalamic stimulation in Parkinsonian and essential tremor. J Neurol Neurosurg Psychiatry. 1999;66(3):289-296.

54. Blomstedt P, Hariz GM, Hariz MI, Koskinen LO. Thalamic deep brain stimulation in the treatment of essential tremor: a long-term follow-up. Br J Neurosurg. 2007;21(5):504-509.

55. Sydow O, Thobois S, Alesch F, Speelman JD. Multicentre European study of thalamic stimulation in essential tremor: a six years follow up. J Neurol Neurosurg Psychiatry. 2003;74(10):1387-1391.

56. Thevathasan W, Schweder P, Joint C, et al. Permanent tremor reduction during thalamic stimulation in multiple sclerosis. J Neurol Neurosurg Psychiatry. 2011;82(4):419-422.

57. Torres CV, Moro E, Lopez-Rios AL, et al. Deep brain stimulation of the ventral intermediate nucleus of the thalamus for tremor in patients with multiple sclerosis. Neurosurgery. 2010;67(3):646-651. [discussion 51].

58. Follett MA, Torres-Russotto D, Follett KA. Bilateral deep brain stimulation of the ventral intermediate nucleus of the thalamus for posttraumatic midbrain tremor. Neuromodulation. 2014;17(3):289-291.

59. Nikkhah G, Prokop T, Hellwig B, Lucking CH, Ostertag CB. Deep brain stimulation of the nucleus ventralis intermedius for Holmes (rubral) tremor and associated dystonia caused by upper brainstem lesions. Report of two cases. J Neurosurg. 2004;100(6):1079-1083.

60. Hariz MI, Krack P, Alesch F, et al. Multicentre European study of thalamic stimulation for Parkinsonian tremor: a 6 years follow-up. J Neurol Neurosurg Psychiatry. 2008;79(6):694-699.

61. Geyer HL, Bressman SB. The diagnosis of dystonia. Lancet Neurol. 2006;5(9):780-790.

62. Vitek JL, Chockkan V, Zhang JY, et al. Neuronal activity in the basal ganglia in patients with generalized dystonia and hemiballismus. Ann Neurol. 1999;46(1):22-35.

63. Lenz FA, Suarez JI, Metman LV, et al. Pallidal activity during dystonia: somatosensory reorganisation and changes with severity. $J$ Neurol Neurosurg Psychiatry. 1998;65(5):767-770.

64. Coubes P, Roubertie A, Vayssiere N, Hemm S, Echenne B. Treatment of DYT1-generalised dystonia by stimulation of the internal globus pallidus. Lancet. 2000;355(9222):2220-2221.

65. Tisch S, Rothwell JC, Limousin P, Hariz MI, Corcos DM. The physiological effects of pallidal deep brain stimulation in dystonia. IEEE Trans Neural Syst Rehabil Eng. 2007;15(2):166-172.

66. Kupsch A, Benecke R, Muller J, et al. Pallidal deep-brain stimulation in primary generalized or segmental dystonia. $N$ Engl J Med. 2006; 355(19):1978-1990.

67. Vidailhet M, Vercueil L, Houeto JL, et al. Bilateral deep-brain stimulation of the globus pallidus in primary generalized dystonia. $N$ Engl J Med. 2005;352(5):459-467.

68. Volkmann J, Wolters A, Kupsch A, et al. Pallidal deep brain stimulation in patients with primary generalised or segmental dystonia: 5-year follow-up of a randomised trial. Lancet Neurol. 2012;11(12): 1029-1038.

69. Vidailhet M, Vercueil L, Houeto JL, et al. Bilateral, pallidal, deep-brain stimulation in primary generalised dystonia: a prospective 3 years follow-up study. Lancet Neurol. 2007;6(3):223-229.

70. Fitz Gerald JJ, Rosendal F, de Pennington N, et al. Long-term outcome of deep brain stimulation in generalised dystonia: a series of 60 cases. J Neurol Neurosurg Psychiatry. 2014;85(12):1371-1376.

71. Panov F, Gologorsky Y, Connors G, Tagliati M, Miravite J, Alterman RL. Deep brain stimulation in DYT1 dystonia: a 10-year experience. $\mathrm{Neu}$ rosurgery. 2013;73(1):86-93. [discussion].
72. Vidailhet M, Yelnik J, Lagrange C, et al. Bilateral pallidal deep brain stimulation for the treatment of patients with dystonia-choreoathetosis cerebral palsy: a prospective pilot study. Lancet Neurol. 2009;8(8): 709-717.

73. Volkmann J, Mueller J, Deuschl G, et al. Pallidal neurostimulation in patients with medication-refractory cervical dystonia: a randomised, sham-controlled trial. Lancet Neurol. 2014;13(9):875-884.

74. Vasques X, Cif L, Gonzalez V, Nicholson C, Coubes P. Factors predicting improvement in primary generalized dystonia treated by pallidal deep brain stimulation. Mov Disord. 2009;24(6):846-853.

75. Ostrem JL, Markun LC, Glass GA, et al. Effect of frequency on subthalamic nucleus deep brain stimulation in primary dystonia. Parkinsonism Relat Disord. 2014;20(4):432-438.

76. Ostrem JL, Racine CA, Glass GA, et al. Subthalamic nucleus deep brain stimulation in primary cervical dystonia. Neurology. 2011;76(10):870-878.

77. Schjerling L, Hjermind LE, Jespersen B, et al. A randomized doubleblind crossover trial comparing subthalamic and pallidal deep brain stimulation for dystonia. J Neurosurg. 2013;119(6):1537-1545.

78. Fisher R, Salanova V, Witt T, et al. Electrical stimulation of the anterior nucleus of thalamus for treatment of refractory epilepsy. Epilepsia. 2010;51(5):899-908.

79. Andrade DM, Zumsteg D, Hamani C, et al. Long-term follow-up of patients with thalamic deep brain stimulation for epilepsy. Neurology. 2006;66(10):1571-1573.

80. Kerrigan JF, Litt B, Fisher RS, et al. Electrical stimulation of the anterior nucleus of the thalamus for the treatment of intractable epilepsy. Epilepsia. 2004;45(4):346-354.

81. Lee KJ, Shon YM, Cho CB. Long-term outcome of anterior thalamic nucleus stimulation for intractable epilepsy. Stereotact Funct Neurosurg. 2012;90(6):379-385.

82. Valentin A, Garcia Navarrete E, Chelvarajah R, et al. Deep brain stimulation of the centromedian thalamic nucleus for the treatment of generalized and frontal epilepsies. Epilepsia. 2013;54(10):1823-1833.

83. Velasco AL, Velasco F, Velasco M, Trejo D, Castro G, Carrillo-Ruiz JD. Electrical stimulation of the hippocampal epileptic foci for seizure control: a double-blind, long-term follow-up study. Epilepsia. 2007;48(10):1895-1903.

84. McLachlan RS, Pigott S, Tellez-Zenteno JF, Wiebe S, Parrent A. Bilateral hippocampal stimulation for intractable temporal lobe epilepsy: impact on seizures and memory. Epilepsia. 2010;51(2): 304-307.

85. Cukiert A, Cukiert CM, Burattini JA, Lima AM. Seizure outcome after hippocampal deep brain stimulation in a prospective cohort of patients with refractory temporal lobe epilepsy. Seizure. 2014; 23(1):6-9.

86. Tellez-Zenteno JF, McLachlan RS, Parrent A, Kubu CS, Wiebe S. Hippocampal electrical stimulation in mesial temporal lobe epilepsy. Neurology. 2006;66(10):1490-1494.

87. Boon P, Vonck K, De Herdt V, et al. Deep brain stimulation in patients with refractory temporal lobe epilepsy. Epilepsia. 2007;48(8):1551-1560.

88. Boex C, Seeck M, Vulliemoz S, et al. Chronic deep brain stimulation in mesial temporal lobe epilepsy. Seizure. 2011;20(6):485-490.

89. Bondallaz P, Boex C, Rossetti AO, et al. Electrode location and clinical outcome in hippocampal electrical stimulation for mesial temporal lobe epilepsy. Seizure. 2013;22(5):390-395.

90. Capecci M, Ricciuti RA, Ortenzi A, et al. Chronic bilateral subthalamic stimulation after anterior callosotomy in drug-resistant epilepsy: long-term clinical and functional outcome of two cases. Epilepsy Res. 2012;98(2-3):135-139.

91. Wille C, Steinhoff BJ, Altenmuller DM, et al. Chronic high-frequency deep-brain stimulation in progressive myoclonic epilepsy in adulthood - report of five cases. Epilepsia. 2011;52(3):489-496.

92. Nuttin B, Cosyns P, Demeulemeester H, Gybels J, Meyerson B. Electrical stimulation in anterior limbs of internal capsules in patients with obsessive-compulsive disorder. Lancet. 1999; 354(9189):1526. 
93. Nuttin BJ, Gabriels LA, Cosyns PR, et al. Long-term electrical capsular stimulation in patients with obsessive-compulsive disorder. Neurosurgery. 2003;52(6):1263-1272. [discussion 72-74].

94. Greenberg BD, Malone DA, Friehs GM, et al. Three-year outcomes in deep brain stimulation for highly resistant obsessive-compulsive disorder. Neuropsychopharmacology. 2006;31(11):2384-2393.

95. Greenberg BD, Gabriels LA, Malone DA Jr, et al. Deep brain stimulation of the ventral internal capsule/ventral striatum for obsessivecompulsive disorder: worldwide experience. Mol Psychiatry. 2010;15(1):64-79.

96. Sturm V, Lenartz D, Koulousakis A, et al. The nucleus accumbens: a target for deep brain stimulation in obsessive-compulsive- and anxiety-disorders. J Chem Neuroanat. 2003;26(4):293-299.

97. Huff W, Lenartz D, Schormann M, et al. Unilateral deep brain stimulation of the nucleus accumbens in patients with treatment-resistant obsessive-compulsive disorder: outcomes after one year. Clin Neurol Neurosurg. 2010;112(2):137-143.

98. Denys D, Mantione M, Figee M, et al. Deep brain stimulation of the nucleus accumbens for treatment-refractory obsessive-compulsive disorder. Arch Gen Psychiatry. 2010;67(10):1061-1068.

99. van den Munckhof P, Bosch DA, Mantione MH, Figee M, Denys DA, Schuurman PR. Active stimulation site of nucleus accumbens deep brain stimulation in obsessive-compulsive disorder is localized in the ventral internal capsule. Acta Neurochir Suppl. 2013; 117:53-59.

100. Mallet L, Polosan M, Jaafari N, et al. Subthalamic nucleus stimulation in severe obsessive-compulsive disorder. $N$ Engl J Med. 2008;359(20):2121-2134.

101. Hamani C, Pilitsis J, Rughani AI, et al. Deep brain stimulation for obsessive-compulsive disorder: systematic review and evidencebased guideline sponsored by the American Society for Stereotactic and Functional Neurosurgery (ASSFN) and the Congress of Neurological Surgeons (CNS) and Endorsed by the CNS and American Association of Neurological Surgeons (AANS). Neurosurgery. 2014;75(4):327-333.

102. Mayberg HS, Lozano AM, Voon V, et al. Deep brain stimulation for treatment-resistant depression. Neuron. 2005;45(5):651-660.

103. Lozano AM, Mayberg HS, Giacobbe P, Hamani C, Craddock RC, Kennedy SH. Subcallosal cingulate gyrus deep brain stimulation for treatment-resistant depression. Biol Psychiatry. 2008;64(6):461-467.

104. Kennedy SH, Giacobbe P, Rizvi SJ, et al. Deep brain stimulation for treatment-resistant depression: follow-up after 3 to 6 years. $\mathrm{Am} \mathrm{J}$ Psychiatry. 2011;168(5):502-510.

105. Holtzheimer PE, Kelley ME, Gross RE, et al. Subcallosal cingulate deep brain stimulation for treatment-resistant unipolar and bipolar depression. Arch Gen Psychiatry. 2012;69(2):150-158.

106. Hamani C, Mayberg H, Stone S, Laxton A, Haber S, Lozano AM. The subcallosal cingulate gyrus in the context of major depression. Biol Psychiatry. 2011;69(4):301-308.

107. Schlaepfer TE, Cohen MX, Frick C, et al. Deep brain stimulation to reward circuitry alleviates anhedonia in refractory major depression. Neuropsychopharmacology. 2008;33(2):368-377.

108. Bewernick BH, Hurlemann R, Matusch A, et al. Nucleus accumbens deep brain stimulation decreases ratings of depression and anxiety in treatment-resistant depression. Biol Psychiatry. 2010;67(2):110-116.

109. Bewernick BH, Kayser S, Sturm V, Schlaepfer TE. Long-term effects of nucleus accumbens deep brain stimulation in treatment-resistant depression: evidence for sustained efficacy. Neuropsychopharmacology. 2012;37(9):1975-1985.

110. Malone DA Jr, Dougherty DD, Rezai AR, et al. Deep brain stimulation of the ventral capsule/ventral striatum for treatment-resistant depression. Biol Psychiatry. 2009;65(4):267-275.

111. Coenen VA, Schlaepfer TE, Maedler B, Panksepp J. Cross-species affective functions of the medial forebrain bundle-implications for the treatment of affective pain and depression in humans. Neurosci Biobehav Rev. 2011;35(9):1971-1981.
112. Schlaepfer TE, Bewernick BH, Kayser S, Madler B, Coenen VA. Rapid effects of deep brain stimulation for treatment-resistant major depression. Biol Psychiatry. 2013;73(12):1204-1212.

113. Jimenez F, Velasco F, Salin-Pascual R, et al. A patient with a resistant major depression disorder treated with deep brain stimulation in the inferior thalamic peduncle. Neurosurgery. 2005;57(3):585-593. [discussion-93].

114. Sartorius A, Kiening KL, Kirsch P, et al. Remission of major depression under deep brain stimulation of the lateral habenula in a therapyrefractory patient. Biol Psychiatry. 2010;67(2):e9-e11.

115. Hikosaka O. The habenula: from stress evasion to value-based decision-making. Nat Rev Neurosci. 2010;11(7):503-513.

116. Hikosaka O, Sesack SR, Lecourtier L, Shepard PD. Habenula: crossroad between the basal ganglia and the limbic system. J Neurosci. 2008;28(46):11825-11829.

117. Mink JW. Basal ganglia dysfunction in Tourette's syndrome: a new hypothesis. Pediatr Neurol. 2001;25(3):190-198.

118. Vandewalle V, van der Linden C, Groenewegen HJ, Caemaert J. Stereotactic treatment of Gilles de la Tourette syndrome by high frequency stimulation of thalamus. Lancet. 1999;353(9154): 724 .

119. Ackermans L, Duits A, van der Linden C, et al. Double-blind clinical trial of thalamic stimulation in patients with Tourette syndrome. [Randomized Controlled Trial]. Brain. 2011;134(pt 3):832-844.

120. Bajwa RJ, de Lotbiniere AJ, King RA, et al. Deep brain stimulation in Tourette's syndrome. Mov Disord. 2007;22(9):1346-1350.

121. Idris Z, Ghani AR, Mar W, et al. Intracerebral haematomas after deep brain stimulation surgery in a patient with Tourette syndrome and low factor XIIIA activity. J Clin Neurosci. 2010;17(10):1343-1344.

122. Janik P, Koziara H, Mandat T. Deep brain stimulation of CM-SPv-Voi complex for alleviating symptoms of Tourette syndrome. Parkinsonism Relat Disord. 2009;15:S30.

123. Maciunas RJ, Maddux BN, Riley DE, et al. Prospective randomized double-blind trial of bilateral thalamic deep brain stimulation in adults with Tourette syndrome. J Neurosurg. 2007;107(5):1004-1014.

124. Shields DC, Cheng ML, Flaherty AW, Gale JT, Eskandar EN. Microelectrode-guided deep brain stimulation for Tourette syndrome: within-subject comparison of different stimulation sites. Stereotact Funct Neurosurg. 2008;86(2):87-91.

125. Visser-Vandewalle V, Temel Y, Boon P, et al. Chronic bilateral thalamic stimulation: a new therapeutic approach in intractable Tourette syndrome. Report of three cases. J Neurosurg. 2003; 99(6):1094-1100.

126. Porta M, Brambilla A, Cavanna AE, et al. Thalamic deep brain stimulation for treatment-refractory Tourette syndrome: two-year outcome. Neurology. 2009;73(17):1375-1380.

127. Servello D, Porta M, Sassi M, Brambilla A, Robertson MM. Deep brain stimulation in 18 patients with severe Gilles de la Tourette syndrome refractory to treatment: the surgery and stimulation. J Neurol Neurosurg Psychiatry. 2008;79(2):136-142.

128. Servello D, Sassi M, Brambilla A, Defendi S, Porta M. Long-term, post-deep brain stimulation management of a series of 36 patients affected with refractory gilles de la Tourette syndrome. Neuromodulation. 2010;13(3):187-194.

129. Houeto JL, Karachi C, Mallet L, et al. Tourette's syndrome and deep brain stimulation. J Neurol Neurosurg Psychiatry. 2005;76(7): 992-995.

130. Vernaleken I, Kuhn J, Janouschek H, et al. Acute and chronic effects of bithalamic deep brain stimulation on dopaminergic transmission. Neuroimage. 2010;52:S103.

131. Vernaleken I, Kuhn J, Lenartz D, et al. Bithalamical deep brain stimulation in Tourette syndrome is associated with reduction in dopaminergic transmission. Biol Psychiatry. 2009;66(10):e15-e17.

132. Vilela Filho O, Ragazzo PC, Silva DJ, Souza JT, Oliveira PM, Ribeiro TMC. Deep Brain Stimulation (GPe-DBS) for the treatment of Tourette syndrome: an ongoing prospective controlled study. Stereotact Funct Neurosurg. 2007;85:42-43. 
133. Dehning S, Mehrkens JH, Muller N, Botzel K. Therapy-refractory Tourette syndrome: beneficial outcome with globus pallidus internus deep brain stimulation. Mov Disord. 2008;23(9):1300-1302.

134. Diederich NJ, Kalteis K, Stamenkovic M, Pieri V, Alesch F. Efficient internal pallidal stimulation in Gilles de la Tourette syndrome: a case report. Mov Disord. 2005;20(11):1496-1499.

135. Dueck A, Wolters A, Wunsch K, et al. Deep brain stimulation of globus pallidus internus in a 16-year-old boy with severe Tourette syndrome and mental retardation. Neuropediatrics. 2010;40(05):239-242.

136. Foltynie T, Martinez-Torres I, Zrinzo L, et al. Improvement in vocal and motor tics following DBS of motor GPi for Tourette syndrome, not accompanied by subjective improvement in quality of life - a case report. Mov Disord. 2009;24:S497-S498.

137. Gallagher CL, Garell PC, Montgomery EB Jr. Hemi tics and deep brain stimulation. Neurology. 2006;66(3):E12.

138. Shahed J, Poysky J, Kenney C, Simpson R, Jankovic J. GPi deep brain stimulation for Tourette syndrome improves tics and psychiatric comorbidities. Neurology. 2007;68(2):159-160.

139. Van der Linden C, Colle H, Vandewalle V, Alessi G, Rijckaert D, De Waele L. Successful treatment of tics with bilateral internal pallidum (GPi) stimulation in a 27-year-old male patient with Gilles de la Tourette's syndrome. Mov Disord. 2002;17:S341.

140. Burdick A, Foote KD, Goodman W, et al. Lack of benefit of accumbens/capsular deep brain stimulation in a patient with both tics and obsessive-compulsive disorder. Neurocase. 2010;16(4):321-330.

141. Kuhn J, Lenartz D, Mai JK, et al. Deep brain stimulation of the nucleus accumbens and the internal capsule in therapeutically refractory Tourette-syndrome. [Letter]. J Neurol. 2007;254(7):963-965.

142. Neuner I, Podoll K, Lenartz D, Sturm V, Schneider F. Deep brain stimulation in the nucleus accumbens for intractable Tourette's syndrome: follow-up report of 36 months. Biol Psychiatry. 2009;65(4):e5-e6.

143. Servello D, Sassi M, Brambilla A, et al. De novo and rescue DBS leads for refractory Tourette syndrome patients with severe comorbid OCD: a multiple case report. J Neurol. 2009;256(9):1533-1539.

144. Zabek M, Sobstyl M, Koziara H, Dzierzecki S. Deep brain stimulation of the right nucleus accumbens in a patient with Tourette syndrome. Case report. Neurol Neurochir Pol. 2008;42(6):554-559.

145. Martinez-Torres I, Hariz MI, Zrinzo L, Foltynie T, Limousin P. Improvement of tics after subthalamic nucleus deep brain stimulation. Neurology. 2009;72(20):1787-1789.

146. Pansaon Piedad JC, Rickards HE, Cavanna AE. What patients with gilles de la Tourette syndrome should be treated with deep brain stimulation and what is the best target? Neurosurgery. 2012;71(1):173-192.

147. Groenewegen HJ, van den Heuvel OA, Cath DC, Voorn P, Veltman DJ Does an imbalance between the dorsal and ventral striatopallidal systems play a role in Tourette's syndrome? A neuronal circuit approach. [Review]. Brain Dev. 2003;25(suppl 1):S3-S14.

148. Temel Y, Hescham SA, Jahanshahi A, et al. Neuromodulation in psychiatric disorders. Int Rev Neurobiol. 2012;107:283-314.

149. Walker FO. Huntington's disease. Lancet. 2007;369(9557): 218-228.

150. Moro E, Lang AE, Strafella AP, et al. Bilateral globus pallidus stimulation for Huntington's disease. Ann Neurol. 2004;56(2):290-294.

151. Kang GA, Heath S, Rothlind J, Starr PA. Long-term follow-up of pallidal deep brain stimulation in two cases of Huntington's disease. J Neurol Neurosurg Psychiatry. 2011;82(3):272-277.

152. Lopez-Sendon Moreno JL, Garcia-Caldentey J, Regidor I, del Alamo M, Garcia de Yebenes J. A 5-year follow-up of deep brain stimulation in Huntington's disease. Parkinsonism Relat Disord. 2014;20(2):260-261.

153. Biolsi B, Cif L, Fertit HE, Robles SG, Coubes P. Long-term follow-up of Huntington disease treated by bilateral deep brain stimulation of the internal globus pallidus. J Neurosurg. 2008;109(1):130-132.

154. Gonzalez V, Cif L, Biolsi B, et al. Deep brain stimulation for Huntington's disease: long-term results of a prospective open-label study. J Neurosurg. 2014;121(1):114-122.
155. Spielberger S, Hotter A, Wolf E, et al. Deep brain stimulation in Huntington's disease: a 4-year follow-up case report. Mov Disord. 2012;27(6):806-807. [author reply 7-8].

156. Velez-Lago FM, Thompson A, Oyama G, et al. Differential and better response to deep brain stimulation of chorea compared to dystonia in Huntington's disease. Stereotact Funct Neurosurg. 2013;91(2):129-133.

157. Fasano A, Mazzone P, Piano C, Quaranta D, Soleti F, Bentivoglio AR. GPi-DBS in Huntington's disease: results on motor function and cognition in a 72-year-old case. Mov Disord. 2008;23(9): 1289-1292.

158. Hebb MO, Garcia R, Gaudet P, Mendez IM. Bilateral stimulation of the globus pallidus internus to treat choreathetosis in Huntington's disease: technical case report. Neurosurgery. 2006;58(2):E383. [discussion E].

159. Ligot N, Krystkowiak P, Simonin C, et al. External globus pallidus stimulation modulates brain connectivity in Huntington's disease. $J$ Cereb Blood Flow Metab. 2011;31(1):41-46.

160. Hamani C, McAndrews MP, Cohn M, et al. Memory enhancement induced by hypothalamic/fornix deep brain stimulation. Ann Neurol. 2008;63(1):119-123.

161. Laxton AW, Tang-Wai DF, McAndrews MP, et al. A phase I trial of deep brain stimulation of memory circuits in Alzheimer's disease. Ann Neurol. 2010;68(4):521-534.

162. Suthana N, Haneef Z, Stern J, et al. Memory enhancement and deep-brain stimulation of the entorhinal area. N Engl J Med. 2012;366(6):502-510.

163. Hardenacke K, Kuhn J, Lenartz D, et al. Stimulate or degenerate: deep brain stimulation of the nucleus basalis Meynert in Alzheimer dementia. World Neurosurg. 2013;80(3-4):e35-e43.

164. Freund HJ, Kuhn J, Lenartz D, et al. Cognitive functions in a patient with Parkinson-dementia syndrome undergoing deep brain stimulation. Arch Neurol. 2009;66(6):781-785.

165. Kuhn J, Hardenacke K, Lenartz D, et al. Deep brain stimulation of the nucleus basalis of Meynert in Alzheimer's dementia. Mol Psychiatry. Epub 2014 May 6.

166. Treasure J, Claudino AM, Zucker N. Eating disorders. Lancet 2010;375(9714):583-593.

167. McLaughlin NC, Didie ER, Machado AG, Haber SN, Eskandar EN Greenberg BD. Improvements in anorexia symptoms after deep brain stimulation for intractable obsessive-compulsive disorder. Biol Psychiatry. 2013;73(9):e29-e31.

168. Israel M, Steiger H, Kolivakis T, McGregor L, Sadikot AF. Deep brain stimulation in the subgenual cingulate cortex for an intractable eating disorder. Biol Psychiatry. 2010;67(9):e53-e54.

169. Lipsman N, Woodside DB, Giacobbe P, et al. Subcallosal cingulate deep brain stimulation for treatment-refractory anorexia nervosa: a phase 1 pilot trial. Lancet. 2013;381(9875):1361-1370.

170. Wu H, Van Dyck-Lippens PJ, Santegoeds R, et al. Deep-brain stimulation for anorexia nervosa. World Neurosurg. 2013;80(3-4) e1-e10.

171. Kuhn J, Lenartz D, Huff W, et al. Remission of alcohol dependency following deep brain stimulation of the nucleus accumbens: valuable therapeutic implications? J Neurol Neurosurg Psychiatry. 2007;78(10):1152-1153

172. Kuhn J, Bauer R, Pohl S, et al. Observations on unaided smoking cessation after deep brain stimulation of the nucleus accumbens. Eur Addict Res. 2009;15(4):196-201.

173. Voges J, Muller U, Bogerts B, Munte T, Heinze HJ. Deep brain stimulation surgery for alcohol addiction. World Neurosurg. 2013;80(3-4):e1-e31.

174. Kuhn J, Moller M, Treppmann JF, et al. Deep brain stimulation of the nucleus accumbens and its usefulness in severe opioid addiction. $\mathrm{Mol}$ Psychiatry. 2014;19(2):145-146.

175. Valencia-Alfonso CE, Luigjes J, Smolders R, et al. Effective deep brain stimulation in heroin addiction: a case report with complementary intracranial electroencephalogram. Biol Psychiatry. 2012; 71(8):e35-e37. 
176. Zhou H, Xu J, Jiang J. Deep brain stimulation of nucleus accumbens on heroin-seeking behaviors: a case report. Biol Psychiatry. 2011;69(11):e41-e42.
177. Witjas T, Baunez C, Henry JM, et al. Addiction in Parkinson's disease: impact of subthalamic nucleus deep brain stimulation. Mov Disord. 2005;20(8):1052-1055.

\section{Publish your work in this journal}

Neuropsychiatric Disease and Treatment is an international, peerreviewed journal of clinical therapeutics and pharmacology focusing on concise rapid reporting of clinical or pre-clinical studies on a range of neuropsychiatric and neurological disorders. This journal is indexed on PubMed Central, the 'PsycINFO' database and CAS, and is the official journal of The International Neuropsychiatric Association (INA). The manuscript management system is completely online and includes a very quick and fair peer-review system, which is all easy to use. Visit http://www.dovepress.com/testimonials.php to read real quotes from published authors. 